\title{
Iván Molina Jiménez, La educación en Costa Rica de la época colonial al presente ${ }^{1}$
}

\author{
Juan Alfonseca Giner de los Ríos²
}

Recepción: 20 de marzo de 2017 / Aprobación: 19 de junio de 2017

Con sus poco más de 700 páginas, el libro La educación en Costa Rica de la época colonial al presente del historiador Iván Molina Jiménez es una obra llamada a destacar no solo por los aportes que realiza al desarrollo de la historia de la educación en Costa Rica, sino por lo que su edición representa en el marco general de la historiografía educacional de nuestro continente. Se trata de un bien armado estudio general sobre el desarrollo del sistema escolar costarricense entre fines del siglo XVI y los inicios del XXI, esencialmente interesado en captar las dinámicas que afectaron su emergencia y expansión en el tejido social costarricense a lo largo de 400 años de historia. En este sentido, La educación en Costa Rica de la época colonial al presente constituye una historia de larga duración sobre el desarrollo del proceso de escolarización en Costa Rica, definidamente más inclinada al análisis de las interacciones entre la vida social y la expansión de la escuela que al tratamiento de sus dimensiones pedagógicas, jurídicas e institucionales.

El libro consta de diez capítulos, distribuidos en tres partes o segmentos de periodización histórica, coronadas por un segmento de conclusiones. La primera de las partes -titulada "La formación del sistema educativo"- se dedica a examinar la emergencia y configuración de un sistema de escuelas públicas en el país entre 1580 y 1892, esto es, desde la sociedad colonial hasta los primeros años de implantación de la reforma educativa decretada en 1886 por el ministro Mauro Fernández Acuña. Esta parte abre su análisis con el influjo de la Constitución de Cádiz de 1812 en el establecimiento de la escuela pública en el territorio costarricense, para pasar a examinar luego su paulatina difusión durante la etapa independiente bajo la gestión del nivel municipal hasta la reforma educacional de carácter uniformador y centralizador de 1886.

La segunda se titula "El sistema educativo reformado" y comprende el lapso 1893-1949. Se dedica al estudio de la implementación de la reforma de 1886, que fue la que instauró en Costa Rica un sistema nacional de escuela pública

1 San José, Editoriales Públicas Costarricenses, Consejo Nacional de Rectores y Programa Estado de la Nación, 2016.

2 Dominicano. Doctor en Estudios Latinoamericanos por la Universidad Nacional Autónoma de México (UNAM). Investigador Educativo en el Instituto Superior de Ciencias de la Educación del Estado de México (ISCEEM). Correo electrónico: j_alfonseca@yahoo.es 
para las masas, sobre la base, claro está, de la rearticulación centralizada del poder social y político que había sustentado hasta entonces la enseñanza y del desplazamiento de viejos actores, jurisdicciones y epistemologías sociales sobre la escolarización.

La tercera parte lleva por título "La modernización insuficiente" y centra su análisis en la expansión del sistema entre 1950 y 2014, años en los que este consolida muchas de sus principales características actuales, expandiéndose bajo esa lógica hasta la crisis de financiamiento que emerge en la década de los ochenta con la cauda de contradicciones, desgastes y transformaciones que caracterizaron la llamada Década Perdida y que abrieron el debate por la escuela pública no solo en Costa Rica sino en el orden internacional.

El segmento de conclusiones lleva por título "Un millón de años" y en él quedan esquemáticamente planteados los hallazgos generales sobre las tendencias de larga duración en la formación y el desarrollo del sistema educativo costarricense desde las Reformas Borbónicas al presente. Molina enuncia allí (justo al concluir la crítica de un escrito aparecido en 1939 en una revista publicada por maestros comunistas donde se insinuaba que la aparición de la escuela pública (como política social del Estado) había permitido trascender un estadio de deterioro educacional en el que el sistema escolar era predominantemente privado, la que vendría siendo la tesis principal de la obra:

La característica fundamental del sistema educativo costarricense, desde finales del siglo XVIII e inicios del XIX, fue -en contraste con lo indicado por los editores de Triquitraque- la condición decisivamente pública de la primaria, primero reforzada por la Constitución de 1869 y después por la reforma de 1886. Las presiones de las comunidades urbanas y rurales por más y mejor instrucción ... fueron fundamentales para promover esa índole estatal ... El fuerte rechazo a la reforma educativa, liderado por la Iglesia católica y por los políticos contrarios a los círculos que detentaban el poder desde la época de Guardia Gutiérrez, fue canalizado estratégicamente durante la campaña electoral de 1889. El triunfo de la oposición durante esos comicios abrió un nuevo período de ajustes a la reforma, cuyos alcances fueron de larga duración. El sistema educativo, ciertamente, experimentó cambios importantes durante el siglo xx, pero las bases establecidas entre 1886 y 1895 -en particular en lo que se refiere a organización, contenidos y otros aspectos- todavía son reconocibles en la Costa Rica de la década del 2010 (pp. 588-589).

Los planteos del autor sobre los orígenes decididamente públicos del sistema escolar desde fines del siglo XVIII y sobre el peso de la reforma liberal de 1886 en la definición de tendencias generales que se desplazan durante más de 100 años de historia del sistema escolar costarricense, resultan sumamente interesantes y lo llevan a entroncar con las ideas de Fernand Braudel sobre la larga duración como sucesión de movimientos de estructura, y coyuntura, y con las críticas de Francois X. Guerra al liberalismo decimonónico latinoamericano al postular el proyecto de escuela pública como algo que advendría con 
sus gobiernos, velando los alcances que ese proyecto había tenido durante el Antiguo Régimen.

Como los liberales criticados por Guerra, los maestros comunistas afines al régimen del presidente Gutiérrez Zamora en 1939, enarbolaban la escuela pública como algo debido a la acción del moderno Estado nacional, velando una actividad educativa del poder político precedente, que no había sido marginal y que se había debido a la presión de la propia sociedad civil. En este sentido, los hallazgos de Molina habrán de estimular en la comunidad académica costarricense -como estimularon en México en su día los de Guerra- nuevos horizontes en la búsqueda de los orígenes formativos del sistema de enseñanza.

De tanto o mayor interés conceptual resulta, sin embargo, la tesis sobre la reforma educacional como un proceso que logra inscribirse en la larga duración, y que todavía en el presente del sistema escolar costarricense puedan leerse los impactos estructurales de una coyuntura reformista gestada en 1886. También, en este sentido, los hallazgos del autor se sumarán a las perspectivas que invitan a abrir nuestros análisis de la reforma educacional como procesos cuya impronta no se apega, desde luego, al estrecho marco de los períodos de cambio gubernativo, sino que se insertan en un tiempo histórico caracterizado por la sucesión de movimientos de estructura y de coyuntura.

El aporte que realiza Molina a la historiografía educacional costarricense con este libro desborda con creces lo que su autor reconoce cuando precisa que su propósito es "ofrecer una síntesis de la historia de la educación en Costa Rica" (p. xlv) basado en "la vasta bibliografía" (p. xxxvii) existente. Basta analizar con método y justeza el aparato crítico que presenta para darse cuenta que esa es una afirmación presidida por la modestia. Alrededor de 1500 referencias -entre fuentes de primera y segunda mano- se citan en una bibliografía general en la que solo el diez por ciento corresponde a estudios directamente dedicados a aspectos del desarrollo histórico del sistema de enseñanza. La mayoría de las referencias que integran este subconjunto consiste en trabajos relacionados con procesos de factura reciente, figurando entre ellas solo cuatro obras de carácter general sobre la historia de la educación en el país desde su erección como nación independiente. Este recuento sucinto permite valorar el empleo productivo y creativo que el historiador dio al porcentaje restante de fuentes, que involucran no solo informes y otro tipo de reportes sobre el estado de la enseñanza en distintos períodos, sino un extenso conjunto de fuentes relativas a otras esferas de la actividad social, como la demografía, la agricultura, la industria y los oficios, entre otras.

Más que una síntesis fundada en un acervo de conocimiento dado, La educación en Costa Rica de la época colonial al presente constituye un notable esfuerzo intelectual de integración y superación de un conocimiento 
histórico educacional fundamentalmente disperso, en el que Molina logra no solamente un relato integral de largo plazo sobre el desarrollo del sistema educativo en Costa Rica, sino en el que consigue desplazar la mirada tradicionalmente centrada en la esfera jurídico-institucional como hogar del desarrollo histórico de la educación para situarla en el plano de la historia social.

En el logro de ese relato integral Molina realiza un valioso conjunto de aportes. Comenzando por la reconstrucción del propio espacio escolar nacional (esencialmente conocido a través de "la experiencia del Valle central" (p.xlii), según nos dice, que aparece aquí plenamente reflejado a través de un sinnúmero de análisis regionales comparativos basados en un profuso cuerpo de series de indicadores históricos sobre las siete provincias que lo integran) y continuando con aspectos clave para la producción de una historia nacional de la educación, como el tratamiento de períodos menos conocidos (como el lapso 1930-1980, por ejemplo) o el establecimiento de indicadores estables y homogéneos, aptos para la comparación entre regiones y épocas del desarrollo escolar, la obra de Molina resultará de cardinal importancia en el futuro horizonte intelectual de los historiadores de la educación costarricense.

También lo resultará por las operaciones de crítica que realiza en cuanto a las "visiones descriptivas y apologéticas" ( $p$. xliii) que presidieron parte del conocimiento histórico educacional con el que integra su obra. Es, por ejemplo, el caso de las hipótesis que priman sobre el presunto desinterés popular en la enseñanza escolar en el origen de los tropiezos de la reforma centralizadora de 1886, que Molina somete a examen aquí revelándola, antes bien, como efectos del accionar de una cultura escolar ciudadana resistente a la innovación pedagógica pero interesada de modo auténtico en el avance de la escuela. En la nueva interpretación que da a los problemas de implementación de la reforma, Molina no solo pone en juego evidencias de un discurso popular proclive a la instrucción, aunque inconforme con la uniformación centralizadora puesta en marcha por el proceso de reforma, sino que involucra el papel de otros actores de la sociedad civil costarricense, como la Iglesia católica y las facciones sociales asociadas al ejercicio de poder en el nivel municipal. Del mismo modo, la obra ensanchará las perspectivas de la historiografía educacional por su problematización del "dato" útil empleado en la historización de los procesos de avance del sistema escolar. Existe en el libro un interés sistemático por ensanchar las limitaciones factuales presentes en las fuentes asequibles mediante el empleo de nuevas metodologías (como las planteadas, por ejemplo, por Graff y otros clásicos del análisis de la difusión de la letra) y, de modo muy relevante, por la incorporación de datos procedentes de otros campos historiográficos pertinentes para la reconstrucción de los procesos escolares, como la historia agraria, la historia política, la antropología y, de modo general, los estudios sociales. 
En este último aporte -el alejamiento de una historia de la educación preocupada, sobre todo, por el análisis de sus dimensiones jurídicas e institucionales, para situar su materia analítica en el marco más amplio de la historia social de la educación- radica en gran medida el valor de esta obra. Señalar los muchos razonamientos en los que Molina opera como historiador social de la educación costarricense enfrenta el estrecho marco asignado a esta reseña, pero puede decirse que existe en la obra un permanente interés por poner en juego las relaciones entre las configuraciones del poder y la cultura en la vida social costarricense con las modalidades y tendencias de desarrollo del sistema escolar.

Paso tras paso en el curso de su argumentación, el autor persigue entender la escuela en su contexto societal de acción con el propósito de construir hipótesis mejor fundadas sobre su desarrollo histórico. Desde la preocupación por la ausencia de conocimiento respecto del "proceso mediante el cual se configuró, entre padres analfabetas o con un nivel de instrucción muy limitado, un interés profundo y de largo plazo porque sus hijos ... aprendieran a leer y escribir" (p. xxxvi) con que arranca el análisis de la escolarización en las primeras fases del territorio independiente, el libro se halla enteramente presidido por razonamientos que hacen depender el desarrollo de la institución de factores situados fuera de ella. Y, así como pone en juego la hipótesis de que el desarrollo del sistema escolar en sus primeros estadios formativos dependió menos de la difusión del ideario de la llustración que de la estructura del sistema de estatus y jurisdicciones asociados a la escuela, o de la lógica demográfica de una sociedad de agricultores libres en proceso de expansión colonizadora, pone también un gran número de nuevas hipótesis sociales sobre las dinámicas y modalidades de crecimiento de la escolaridad en las fases de desarrollo más recientes.

Visto desde la perspectiva de la historiografía de la educación en América Latina, La educación en Costa Rica de la época colonial al presente merece varios comentarios. El primero de ellos es evidente por sí mismo y consiste en destacarlo como exponente de una historiografía educacional que pocas veces ha figurado en las reuniones académicas internacionales especializadas en un campo que tradicionalmente ha sido alimentado por las reflexiones sobre naciones como Argentina, Brasil, Colombia, Chile y México, entre otras pocas más. Es de desearse que su difusión logre estimular un eventual flujo de participación de estudios sobre este sistema nacional en el seno de una comunidad académica internacional que suele desconocer el caso de la escuela costarricense.

El segundo apunta a valorar el aporte de un libro con vocación de historia nacional de la educación como este en el marco de una historiografía latinoamericana que, de más en más, vino tornándose regionaly microhistórica. Alejándose, desde hace ya varias décadas, de unas historias nacionales de la educación (que adolecían de las limitaciones que Molina justamente destaca 
respecto de la producción costarricense, al criticar sus énfasis en la dimensión jurídico-institucional, su visión apologética sobre el papel del Estado en la formación del sistema y su confusión respecto de la historia de la escuela en el centro político de la nación como expresión de la historia escolar nacional), la moderna historiografía argentina, brasilera, colombiana o mexicana tendió a moverse hacia los estudios regionales, focales y microhistóricos, haciendo suya la problemática metodológica de la "reducción de escala" como recurso heurístico postulada por el historiador italiano Giovanni Levi (1999). Como resultado de esta tendencia en el desarrollo de la historiografía educacional en el área latinoamericana, asistimos hoy a una suerte de "borramiento" del marco nacional en los muy especializados estudios de historia de la educación. Resulta estimulante, por ello, la vuelta al marco nacional como espacio de reflexión y operacionalización de relaciones observables que realiza el historiador Iván Molina, armado de una metodología bien informada de los avances que supuso la "reducción de escala" para el desarrollo de teorías más potentes sobre el desarrollo de los sistemas escolares.

Debe destacarse la profunda labor de compilación y producción de fuentes estadísticas que sustenta el análisis a lo largo de la obra, pues en ella radica uno de los aportes sustantivos que realiza el autor a la historiografía de la educación costarricense al legarle un acervo de indicadores estadísticos sobre el sistema de enseñanza de suma importancia. Pocos de los 127 cuadros y 41 gráficos que integran ese acervo procede directamente de una sola fuente, involucrando la confección de casi todos ellos la compilación de un buen número de datos dispersos. Esta meritoria labor es particularmente importante en relación con las etapas iniciales de formación del sistema escolar en el siglo XIX, cuando tal tipo de indicadores no se hallaba sometido a criterios de producción regulares, estables y unívocos. También debe señalarse el interés de los razonamientos de historia comparada que despliega el autor al establecer relaciones entre los indicadores del sistema educativo costarricense y sus contrapartes del área latinoamericana, sobre todo en las etapas formativas de los sistemas nacionales de enseñanza.

En suma, la edición de este libro resultará de cardinal importancia para la historiografía educacional costarricense y latinoamericana.

\section{Referencias}

Braudel, Fernand (1984). La Historia y las Ciencias Sociales. Madrid: Alianza Editorial.

Graff, Harvey (2003). Introduction to Historical Studies of Literacy. Interchange. 34 (2-3), 123-131.

Guerra, Francois-Xavier. (1995). México: del Antiguo Régimen a la Revolución.

Tomo I. México: Fondo de Cultura Económica. 
Levi, Giovanni. (1999). Sobre microhistoria. En Peter Burke (Ed.). Formas de hacer historia. (3ª reimpresión, pp. 119-143). Madrid: Alianza Universidad. 